LA COMPRENSIÓN Y

RETENCIÓN DEL

\section{MENSAJE INFORMATIVO}

\section{POR LA AUDIENCIA DE}

\section{TELEVISIÓN}

\section{Samia Benaissa Pedriza}

Doctora en Periodismo

Universidad Complutense de Madrid. Facultad de Ciencias de

la Información. Av. Complutense s/n, 28040 Madrid

(España) - Email: samiabenaissaehotmail.com

\section{Resumen}

La capacidad de los espectadores de televisión para comprender y retener información audiovisual es limitada. La saturación informativa en la que se cae constantemente en los informativos de televisión generalista en España no resulta eficaz para mejorar la recepción del mensaje en este medio de comunicación social. Una encuesta practicada entre sesenta voluntarios demostró que, a corto plazo, la audiencia solo es capaz de recordar alrededor del 35\% de las noticias de un informativo de televisión. No obstante, sí es posible mejorar el procesamiento de información por la audiencia de televisión. Los resultados demuestran que el modo de relacionar los códigos audiovisuales en las piezas informativas influye de forma determinante en el recuerdo y en la comprensión de datos. Un alto grado de
Palabras clave

Códigos audiovisuales, relaciones entre códigos audiovisuales, audio visual redundancy, competencia mediática, audiencia de televisión, recuerdo y comprensión de información audiovisual

Key Words

Verbal and visual codes, textpicture correspondence, audio visual redundancy, social media proficiency, television audience, broadcast news comprehension, broadcast news recall

Abstract

Visual and verbal audience capacity to learn and recall information is limited. However,

Spanish news broadcasts are overcrowded with information. A sixty participant survey revealed that the audience is not able to recall a great number of news shortly after watching a news program. The audience performance was unquestionably weak:

only $35 \%$ of the news released was finally recalled. Nevertheless, there are still some options left to improve the way television viewers process information.

Results show that comprehension and recall are definitely influenced by text-picture correspondence in broadcast news.

Strong audiovisual coordination enhances information gain. 
coordinación entre el audio y el video favorece el recuerdo y la comprensión del mensaje, aunque estos empeoran en presencia de imágenes impactantes y cuando se produce una saturación de códigos audiovisuales. Por otro lado, informaciones con grados más bajos de correspondencia entre códigos audiovisuales obtienen tasas más altas de recuerdo y comprensión cuando se introducen otros factores que no implican distraer la atención del espectador en un grado tan elevado como es el caso de las denominadas "imágenes llamativas".
Nevertheless, understanding and recall worsen when an over exposure of pictures, sounds and commentaries occur or when negative emotional visuals appear in news with a high degree of audiovisual redundancy.

\section{Introducción}

La investigación se inserta en el ámbito de la llamada "redundancy", que estudia las relaciones entre los elementos visuales y verbales en los informativos de televisión y sus efectos en el procesamiento del mensaje por la audiencia.

Constituye una primera aportación a los estudios sobre coordinación entre códigos audiovisuales en España en programas informativos del sur de Europa y se suma a los efectuados con anterioridad en Estados Unidos y el norte del continente europeo.

Revisa y actualiza los resultados de investigaciones anteriores desarrolladas desde los años 1970 sobre aspectos relevantes relativos a la capacidad de los televidentes para asimilar información audiovisual, al nivel de comprensión y recuerdo de un mensaje elaborado con distintos grados de coordinación entre códigos audiovisuales y al particular procesamiento de imágenes de alto impacto emotivo. La investigación analiza y compara el comportamiento de la audiencia ante mensajes audiovisuales actuales caracterizados por una mayor complejidad técnica y conceptual en relación a épocas pasadas.

Aborda el estudio del mensaje informativo en cadenas generalistas españolas de televisión desde la perspectiva de las relaciones entre los códigos audiovisuales. Asimismo, analiza los efectos indirectos en la comprensión y retención de información audiovisual por una audiencia de televisión no especializada que consume informativos de televisión al menos una vez por semana.

El estudio tiene por objetivo descubrir modos aptos de elaboración del mensaje que faciliten una recepción eficaz en el medio televisivo y al mismo tiempo detectar disfunciones que dificulten su correcta asimilación. 
Por último, permite conocer el modo de procesar información audiovisual por parte de espectadores con distintos perfiles socio-económicos y culturales en pleno auge del "infoentretenimiento" y de la Sociedad de la Información en España.

\section{Objetivos}

La investigación pretende analizar las distintas relaciones entre códigos audiovisuales y su evolución en la historia de la televisión informativa en España. Se entiende que conocer el modo en que se relacionan los códigos lingüístico, icónico y sonoro es fundamental para abordar el análisis de la competencia mediática de la audiencia de televisión actual. El examen se centra en analizar tipos de relaciones básicas entre elementos audiovisuales en los géneros informativos televisuales de cadenas estadounidenses y españolas desde la década de los años 1970 , momento en que surge entre la doctrina extranjera el interés por la denominada "redundancy". La investigación toma como base de estudio cuatro tipos de relaciones entre códigos audiovisuales cuya presencia habitual se detectó en programas informativos elaborados en distintos países, en idiomas diferentes y con un diverso grado de desarrollo de su respectiva cultura mediática.

El estudio se fija por objetivo, por tanto, examinar el procesamiento de información audiovisual elaborada en función de distintas relaciones entre códigos por la audiencia de televisión. Las relaciones entre códigos examinadas son las codificadas por Mayoral et al. (2008: 184) en función de los criterios de la conexión entre códigos y su presencia o ausencia en las piezas informativas de televisión. Las relaciones entre códigos audiovisuales tomadas como referencia son la relación de jerarquía total (del código lingüístico o del icónico), la relación de jerarquía parcial (del código lingüístico, icónico o sonoro en relación a los demás códigos), la relación de complementariedad perfecta y la relación de complementariedad imperfecta. Estos tipos de relaciones generan distintos grados de correspondencia entre códigos audiovisuales que son susceptibles de influir de forma determinante en el modo en que la audiencia de televisión de la primera década del siglo XXI procesa información audiovisual.

En definitiva, la investigación trata de descubrir las competencias mediáticas de los espectadores de informativos de 
televisión generalista en nuestro país a finales de la década de los años 2000. El momento en que se lleva a cabo la investigación coincide con la aparición de nuevos modos de elaboración del mensaje periodístico en los medios de comunicación, orientados hacia una mayor interconexión de códigos en todo tipo de soportes. La investigación se fija como finalidad hallar la posible existencia de procedimientos alternativos de descodificación de un mensaje audiovisual en el que los códigos au- diovisuales se interrelacionan de una forma mucho más compleja que en el pasado.

En concreto, la investigación aborda el estudio de la capacidad de retención y comprensión del mensaje informativo en función de una serie de variables estrechamente relacionadas con la actual cultura de la imagen y del "infoentretenimiento", siempre desde la perspectiva de las relaciones entre los códigos audiovisuales.

\section{Metodología}

La metodología empleada difiere en función de las distintas fases de la investigación. En la primera fase la metodología fue de tipo descriptivo y centrada en el estudio de casos para el estudio de las relaciones entre los códigos audiovisuales. Se recurrió al método cualitativo y se empleó la técnica de investigación de la observación directa no estructurada para analizar una muestra de noticiarios de televisión y otros programas informativos emitidos por cuatro cadenas de televisión generalista españolas y tres estadounidenses durante las décadas de 1970, 1980, 1990 у 2000.

La muestra formada por noticiarios españoles actuales fue seleccionada entre fuentes primarias de forma alea- toria mediante sorteo de cincuenta y seis ediciones de informativos. Estas correspondieron a noticiarios emitidos por las cadenas de televisión Televisión Española, Antena 3, Telecinco y Cuatro en horario de tarde y noche, de lunes a domingo, durante siete meses consecutivos del año 2009. De forma adicional se seleccionó estratégicamente otra muestra de programas informativos con distintas piezas cuyas características interesaba analizar. Esta segunda muestra se compuso de una edición de un informativo, un programa de noticias, dos programas de reportajes y un especial informativo emitidos por las cadenas de referencia. El análisis histórico de informativos se efectuó a partir de una muestra selec- 
cionada aleatoriamente entre el material de archivo disponible de diecinueve ediciones de informativos y dos programas de reportajes de las cadenas Televisión Española, Antena 3, Telecinco, Cuatro, ABC, CBS y NBC.

Durante la segunda fase se llevó a cabo un experimento entre sesenta voluntarios empleando el método cuantitativo "como investigación" que permitió obtener datos sobre los efectos indirectos en la comprensión y retención del mensaje informativo en televisión. Estos fueron interpretados tanto de forma cuantitativa como cualitativa.

En el experimento participaron sesenta voluntarios de distinto sexo, edad, formación y clase social residentes en las comunidades autónomas de Madrid, Cataluña, Castilla-La Mancha y Principado de Asturias. Para diseñar la muestra de participantes se tomó en cuenta el perfil socio-económico de la audiencia de las cuatro cadenas generalistas con mayor número de espectadores de informativos registrado durante la temporada 2008-2009 en Es- paña. Los datos proporcionados por Televisión Española, Antena 3, Telecinco y Cuatro permitieron configurar una muestra de espectadores muy similar a las características del universo. La selección de participantes se efectuó de forma no probabilística y utilizando el método de selección de cuotas. Se pretendió sondear a la audiencia de forma puntual en el año 2010.

La técnica de investigación empleada para desarrollar el experimento fue la encuesta. Para llevarla a cabo se elaboró un cuestionario de treinta y una preguntas abiertas, cerradas y en escalas de valoración (escala de Likert). Las preguntas versaron sobre el contenido de un informativo de diecinueve piezas y veinticinco minutos de duración especialmente editado para la investigación con material gráfico y de agencia. Del informativo se editaron dos versiones con noticias comunes y alternativas mostradas a dos grupos de treinta personas seleccionadas de forma estratificada que constituyeron los grupos de control y experimental.

\section{La audiencia de televisión en el siglo XXI}

La segunda década del siglo XXI se está caracterizando por un desarrollo intensivo de la Sociedad de la infor- mación a través de distintos canales de comunicación. Los medios digitales y audiovisuales parecen llevar la delan- 
tera a la tradicional prensa escrita tanto en tasa de penetración como en volumen de audiencia. Según datos de la última oleada correspondiente al Estudio General de Medios que realiza la Asociación para la investigación de medios de comunicación, la televisión registró una tasa de penetración del $88,5 \%$, la radio del $58,5 \%$, y los medios digitales de un 42,5\% (ASOCIACIÓN PARA LA INVESTIGACIÓN DE MEDIOS DE COMUNICACIÓN, 2011: web). En términos de audiencia registrada, la televisión mantiene su liderazgo con 34.934.000 espectadores registrados en el año 2011 frente a la radio, que reunió a 23.115.000 oyentes, e Internet, que contabilizó 16.768.000 usuarios en el año móvil de febrero a noviembre de 2011. Estos datos nos ofrecen una idea de lo importante que resulta conocer las características de los públicos objetivo a los que se dirigen los distintos medios de comunicación en la era de lo que el sociólogo Manuel Castells ha denominado la "sociedad red" (Castells, 2004: 3$)^{\mathrm{i}}$.

Ya a mediados de la década de 1990, cuando la sociedad en red era aun embrionaria, el sociólogo francés Pierre Bourdieu se preguntaba, en relación al medio televisivo, si realmente era posible pensar con prisa (Bourdieu, 1996: 30). Dada la rápida sucesión de noticias editadas en tiempo récord $y$ difundidas en los informativos de televisión actuales, es probable que muchas personas hoy se hagan la misma pregunta que Bourdieu. ¿Qué parte de la información así contada se recuerda y se comprende? Quizá se podría pensar que, en la época actual, el ritmo frenético en el que se desarrollan la mayoría de las actividades de la vida cotidiana -y entre ellas la de ver televisión- ha contribuido a desarrollar la capacidad de los espectadores para recordar y asimilar rápidamente la información que se consume cada día como cualquier otro bien fungible.

Sin embargo, los resultados de numerosos estudios llevados a cabo desde la década de 1970 demuestran que del total de noticias emitidas en un informativo solo se recuerda una media de dos o tres (Katz, Adoni y Parness, 1977: 239; Stauffer, Frost y Rybolt, 1983: 29). En el pasado, los esfuerzos por conocer el modo en que la audiencia procesa mensajes audiovisuales en televisión se han realizado en relación con la comprensión y el recuerdo de información en noticiarios y programas informativos de países como Estados Unidos, Reino Unido, Alemania o Países Bajos, desde la década de 1970 hasta la actualidad. La investigación realizada en nuestro país a lo largo del año 2010 y que ahora se presenta profundiza en el conocimiento de la audiencia en ese sentido y aporta 
datos sobre la competencia mediática real de los espectadores alcanzada a principios del siglo XXI.

Tradicionalmente, el análisis de la audiencia de televisión se ha efectuado desde un punto de vista cuantitativo. Los estudios de audiencias suelen priorizar el uso de una metodología cuantitativa que permite obtener datos estadísticos, contables y codificables. Pero, sin perjuicio de las indudables ventajas que este tipo de investigaciones ofrece a la hora de manejar grandes muestras de población, es indudable que la propia esencia del método cuantitativo origina ciertas limitaciones cuando se trata de obtener datos de naturaleza esencialmente cualitativa, como pueden ser aquellos que versan sobre la capacidad de comprensión de los mensajes, la retención de los datos transmitidos por los medios de comunicación o el modo de procesar la información generada mediante el recurso a una pluralidad de códigos -texto, imágenes y sonidos relacionados en mayor menor medida-. Estas cuestiones han constituido el objeto de la presente investigación sobre la llamada "redundancy" que estudia las relaciones entre los códigos audiovisuales y sus efectos en la comprensión y retención de los mensajes informativos por la audiencia de televisión.
La investigación aborda el estudio de los efectos indirectos del mensaje informativo en televisión desde la perspectiva de los códigos audiovisuales. Recurre al método cuantitativo "como investigación" que interpreta de forma cualitativa los datos registrados de forma cuantitativa. El análisis del comportamiento de la audiencia televisiva se efectuó mediante un experimento científico en el que participaron sesenta voluntarios con distintos perfiles asociados a las características de la audiencia de televisión generalista de cuatro cadenas españolas que emiten informativos de televisión en abierto: Televisión Española, Antena 3, Telecinco y Cuatro.

El estudio trató distintas cuestiones relacionadas con el modo de procesar el mensaje informativo en el medio televisivo por una audiencia no especializada. Tomó en cuenta una serie de teorías previamente enunciadas por la doctrina sobre la capacidad de los receptores para comprender y recordar información transmitida por vía audiovisual para, a continuación, elaborar un análisis de la situación actual en nuestro país en relación al modo de asimilar la información en televisión. Algunas de estas teorías se refieren al volumen de información recordada por los espectadores (Stauffer, Frost y Rybolt, 1983: 29), a los efectos de distintos grados de coordinación entre 
los códigos audiovisuales en el recuerdo y comprensión del mensaje (Son, Reese y Davie, 1987: 207-216; Brosius et. al, 1996: 180) o al modo de asimilar el mensaje cuando se emiten imágenes de alto impacto emotivo (Newhagen, 1992: 34-38; Lang, Newhagen y Reeves, 1996: 460), entre otras.

La investigación partió de una elaboración teórica sobre los códigos audiovisuales que distingue cuatro relaciones básicas entre el texto, las imágenes y los sonidos: relación de jerarquía total $^{\mathrm{ii}}$, relación de jerarquía parcialii, relación de complementariedad perfec$\mathrm{ta}^{\mathrm{iv}}$ y relación de complementariedad imperfecta $^{\mathrm{v}}$ (Mayoral et. al, 2008: 184). Es significativa la escasa literatura científica tanto nacional como extranjera que tipifica el modo en que los tres códigos audiovisuales se coordinan en los géneros periodísticos. En nuestro país, solamente se pueden citar como referencias previas a la de Mayoral et al. las aportaciones de Jaime Barroso que destaca tres tipos de relaciones de "concordancia o coherencia", de "neutralidad" y de "distorsión/contracción” (Barroso, 1992: 242) y las de José Prósper y Celestino J. López que hablan de relaciones de "redundancia", "complementariedad" e "incongruencia" (Prósper y López, 1998: 23-24). Los autores extranjeros hablan de distintos grados de coordi- nación entre códigos audiovisuales "audiovisual redundancy" en la terminología anglosajona- (Zhou, 2005: 24), pero sin referirse en concreto a las distintas formas en las que se relacionan los códigos audiovisuales.

Esta escasez de referencias teóricas se explica por el hecho de que resulta difícil definir con exhaustividad todos los tipos de relaciones entre códigos audiovisuales que pueden surgir en las distintas piezas informativas emitidas en los programas informativos de televisión. Sin embargo, se entiende que sí es posible establecer una clasificación básica que recoja las principales formas de relacionar texto, imágenes y sonidos con la finalidad de estudiar su influencia en el procesamiento de información audiovisual por la audiencia actual de televisión. Se tomó como referencia la clasificación más actual de Mayoral et al. ya que incluye otros criterios además del grado bajo, medio $o$ alto entre el audio y el video que utilizaron los autores citados en la década de los años 1990. Estos criterios son la presencia o ausencia de los respectivos códigos audiovisuales y su grado de coordinación, un aspecto relevante para el análisis del comportamiento de la audiencia de finales de los años 2000 a la hora de interpretar y recordar información audiovisual. 
La elaboración de una tipología de relaciones entre códigos audiovisuales en los informativos de televisión es relevante por cuanto sirve de base para elaborar distintos mensajes informativos que pueden ser mejor o peor comprendidos y/o recordados por los espectadores. Se analizaron distintos factores susceptibles de influir en el procesamiento de información en función de las cuatro relaciones entre códigos audiovisuales de referencia tales como la estructura narrativa, el uso de imágenes de impacto o los formatos televisivos, entre otros. Finalmente, el experimento practicado reveló información actualizada sobre la capacidad y competencia audiovisual de los espectadores en el medio de comunicación que cuenta con el mayor número de receptores en la actualidad.

\section{El procesamiento de información audiovisual en la historia de la televisión informativa}

En la primera fase de la investigación se efectuó el análisis de una muestra de informativos de televisión de las cuatro cadenas tomadas como referencia (Televisión Española, Antena 3, Telecinco y Cuatro) emitidos durante las décadas de 1970, 1980, 1990 y 2000. Se empleó la técnica de la observación directa no estructurada sobre una selección aleatoria mediante sorteo de cincuenta y seis ediciones de informativos. A esta muestra se añadió otra más reducida compuesta por una edición de informativos, un programa de noticias, dos programas de reportajes y un especial informativo seleccionados de forma estratégica entre el material de archivo disponible de las cadenas de televisión estadounidenses $\mathrm{ABC}$,
CBS y NBC con el objetivo de comparar la evolución de la producción audiovisual informativa a lo largo del tiempo y en función de la distinta cultura audiovisual de dos países con tradiciones mediáticas diferentes.

La observación directa de las muestras de informativos de televisión seleccionadas permitió obtener algunas conclusiones respecto a la elaboración del mensaje audiovisual y a la forma de procesar este tipo de información por la audiencia de televisión en España durante cuatro décadas de su historia.

Puede afirmarse que la cultura audiovisual de los espectadores españoles corre en paralelo al devenir de la información en televisión la cual ha se- 
guido, a su vez, el ritmo de los avances tecnológicos en el medio. Estos permitieron agilizar las informaciones en un principio consistentes en piezas con un claro predominio del código lingüístico en los años 1970 -cuando lo habitual era encontrar relaciones de jerarquía total del código lingüístico, según la tipología de Mayoral et al. (2008: 184)- hasta el momento actual en el que abundan las relaciones de complementariedad entre códigos. Este tipo de relación entre códigos constituye ahora la base de la narración audiovisual de hechos periodísticos cada vez más complejos que exigen una colaboración más estrecha entre los distintos recursos de audio y video disponibles en cada momento.

La audiencia de televisión en España ha superado en gran medida sus limitaciones iniciales en el procesamiento del mensaje audiovisual. La elaboración de informaciones de naturaleza esencialmente estática, con recursos como fotografías fijas, dibujos o retratos de personalidades que permanecían durante varios segundos ante las pantallas de los receptores de televisión de hace cuarenta años son un indicador de la escasa capacidad de la audiencia para asimilar el mensaje audiovisual. Las piezas informativas eran elaboradas de forma similar a las noticias y reportajes de la prensa escrita donde predominaba claramente el texto escri- to como manifestación básica del código lingüístico. La televisión de los años 1970 tendía por tanto a imitar las características de este medio de comunicación, por entonces todavía hegemónico. Se aprecia en la época una cierta dificultad de la audiencia para adaptar la recepción de los mensajes al medio audiovisual. Sobre todo teniendo en cuenta, además, el lenguaje empleado en los informativos que incluía términos y expresiones en muchos casos inaccesibles para la comprensión de un ciudadano de cultura media de la España de finales de los años 1970.

La década de los años 1980 dio paso a la introducción de recursos propiamente audiovisuales en los informativos de televisión como los rótulos de texto, la técnica de los "encabalgamientos", aun rudimentaria, o la del "hit and run", utilizada básicamente cuando se da una escasez de recursos gráficos y que consiste en la coordinación de los códigos audiovisuales únicamente en momentos puntuales de la pieza. Durante esta etapa, los profesionales del medio tomaron conciencia de la necesidad de mejorar la educación audiovisual de los públicos a los que se dirigían. Hubo un mayor interés por mejorar el recuerdo y la comprensión de los mensajes por los espectadores a través de la inclusión en las piezas de un número mayor de elementos de naturaleza icónica: pizarras, carteles, gráfi- 
cos, barridos con cámara de fotos fijas para intentar dar una impresión de movimiento, etc. Se intentaba aclarar con imágenes la información que por vía textual resultase difícil de comprender por los espectadores.

En los años 1990 se produjo un auge del periodismo interpretativo en los informativos de televisión generalista de nuestro país. En relación al uso de códigos audiovisuales, fue la información gráfica la que más contribuyó a dinamizar la información. A los tradicionales gráficos a pantalla completa se añadieron postproducciones, paint box o animaciones por ordenador que intentaban mejorar la comprensión de aquellos mensajes más complejos para la audiencia. Hubo una tendencia generalizada entre las cadenas por intentar aclarar el contenido de los mensajes con todos aquellos medios que permitía la tecnología y la creatividad de los profesionales. Las imágenes llamativas e impactantes fueron menos habituales en los informativos de lo que serían algunos años después. Todavía por aquella época se tendía a considerar que las imágenes en televisión no constituían por sí mismas unas herramientas tan eficaces para la comprensión como los minutos en pantalla dedicados a un "busto parlante", a un enviado especial en una conexión en directo o al comentario de un analista político. El texto continuó siendo el elemento básico sobre el que se construían las informaciones, adaptándose las imágenes al contenido de la narración. Pero la asimilación de la cultura de la imagen entre los espectadores dio lugar a la elaboración de noticias en las que el texto y las imágenes se relacionaron en un mayor grado de igualdad en comparación con décadas pasadas.

La década de los años 2000 significó un punto de inflexión en la forma de procesar los mensajes en televisión. El llamado "infotainement", unión de los términos "información" y "entretenimiento" en lengua inglesa, se había instalado en los medios de comunicación españoles, si bien con un cierto retraso en relación a otros países desarrollados. La televisión resultó ser el medio mejor posicionado para acoger esta nueva manifestación de la cultura mediática importada de Estados Unidos, cuna del periodismo y también del entretenimiento. El código icónico desplegó gran parte de su potencial informativo, pero también emotivo, en el medio televisivo.

El código icónico ha adoptado un papel predominante en comparación a las primeras décadas de estudio de las relaciones entre los códigos audiovisuales. Las imágenes -impactantes, llamativas o ilustrativas-, se emplean continuamente, casi sin descanso a lo 
largo de cualquier informativo. Es algo común a todas las cadenas el querer llamar la atención del espectador. Ahora las imágenes sí se toman como referencia previa a la hora de redactar los textos que se van a locutar con posterioridad en cada pieza informativa. Respecto a los códigos audiovisuales, se aprecia no solo una mayor coordinación entre ellos sino también un notable desarrollo. Para expresar el código lingüístico se aprovechan todos los recursos técnicos existentes en la actualidad -rótulos, postproducciones- con el fin de mantener intacta su función de transmisión de los datos esenciales del mensaje. Por su parte, el sonido ambiente también ha adquirido una mayor relevancia a la hora de transmitir impresiones que ayudan a contextualizar y mejorar la comprensión de los mensajes en televisión. Por consiguiente, el uso de una variedad mayor de relaciones entre los códigos audiovisuales está dando como resultado unas informaciones más ricas, más ágiles y mejor coordinadas en la mayoría de ocasiones.

\section{El procesamiento de información audiovisual en la actualidad}

El momento mediático en el que nos encontramos -fragmentación de audiencias, concentración de medios de comunicación, aparición de nuevas fuentes de información con origen en redes sociales- unido a las transformaciones de la sociedad y de los receptores de información -cada vez más habituados a obtener datos procedentes de distintos canales de comunicaciónconfigura una situación comunicativa especialmente interesante digna de ser analizada desde el punto de vista de los destinatarios de los mensajes periodísticos. En la segunda parte de la investigación, el interés se centró en el examen de la audiencia de televisión en el año 2010, una fecha asociada a un notable ascenso de las nuevas tecnologías de la información en España y a los efectos de la globalización mediática en los países de nuestro entorno.

En esta segunda fase se practicó un experimento que tenía por objetivo conocer las características y la capacidad de la audiencia para retener y comprender información audiovisual a corto plazo (entre veinticuatro horas y siete días) contenida en un programa informativo de televisión. Se seleccionaron de forma no probabilística sesenta voluntarios y voluntarias con diferente formación académica, con edades comprendidas en varios rangos 
a partir de una edad de veinticinco años y pertenecientes a la clase social media. La muestra diseñada coincidía así con el perfil de audiencia comercial de las cuatro cadenas de televisión generalista que obtuvieron mayor número de espectadores en nuestro país en la temporada 2008-2009. El objetivo perseguido era sondear de forma puntual a la audiencia durante siete meses del año 2010.

El experimento consistió en el visionado por dos grupos de voluntarios -un grupo de control y un grupo experimental- de un informativo de televisión editado en dos versiones con motivo de la investigación y en la contestación de un cuestionario de encuesta de treinta y una preguntas abiertas, cerradas y en escala de valoración.

Los resultados confirmaron las teorías sobre la capacidad limitada de la audiencia avanzadas por Wickens $(1984)^{\text {vi }}$ según las cuales los seres humanos poseen una capacidad restringida para retener información procedente simultáneamente de distintos canales. Los estudios de campo realizados durante el decenio de 1970 anunciaban ya que los espectadores solo eran capaces de recordar entre una y dos noticias de un informativo de televisión. Las cifras obtenidas en estudios experimentales solo incrementaban algo más esa barrera hasta alcanzar la can- tidad de seis o siete piezas recordadas sin ayuda (Berry, 1983: 360). Estos datos coinciden con los obtenidos en el experimento ideado para la investigación desarrollada en el año 2010: los espectadores solo fueron capaces de recordar una media de 6,6 noticias de un informativo de televisión de veinticinco minutos de duración, lo que representa un escaso $35 \%$ del total de noticias emitidas.

En principio, no parece que la capacidad de la audiencia para recordar noticias sin algún tipo de pista o ayuda se haya visto modificada con el paso del tiempo. Al menos, en lo que respecta a la retención de un número concreto de noticias de un informativo de televisión.

Posiblemente pudieran influir en el recuerdo y en la comprensión de información audiovisual otros factores socioculturales tales como la propia evolución de los medios de comunicación social, el surgimiento de otros modos de expresión del mensaje informativo en televisión y la aparición de nuevos soportes de transmisión de la información. En un principio, se podría especular que el volumen de información recordada y asimilada por los televidentes en la actualidad pudiera verse incrementado por una mayor cultura audiovisual de la audiencia, con independencia de factores como la 
edad, el sexo, la clase social o la formación académica. Sin embargo, los resultados conducen a pensar que el recuerdo de información sin ayuda depende en mayor medida de factores cognitivos, relacionados con los límites de la capacidad de los seres humanos para recuperar información almacenada en el cerebro.

Los hallazgos confirmarían las teorías sobre la capacidad limitada de la audiencia enunciadas por la doctrina con anterioridad (Wickens, 1984 ${ }^{\text {vii; }}$ Orive, 1988: 154). Esta constatación parece ser un hecho sobre el que coinciden todos los autores desde hace tiempo. En nuestro país sin ir más lejos, Pedro Orive aseguraba ya en los años 1980 que incluso cuando se hacía un sondeo durante la emisión de un informativo, los espectadores encuestados eran incapaces de concretar sobre qué había tratado el noticiario (Orive, 1988: 154).

Por otra parte, el experimento practicado en la investigación reveló información sobre la intensidad del recuerdo de información audiovisual a lo largo de un informativo de televisión. Se advirtió que la audiencia recuerda con mayor facilidad y sin ayuda las noticias emitidas en el primer tercio de duración de un informativo. Entre el $78 \%$ y el $86 \%$ de los espectadores fue capaz de recordar espontáneamente noticias emitidas durante la primera parte del informativo editado especialmente para la investigación. Pero el nivel de concentración de los televidentes tiende a decaer con el transcurso del tiempo, por lo que es durante el último tercio de un programa de noticias cuando los espectadores presentan tasas de recuerdo más heterogéneas. La encuesta a sesenta participantes reveló que el porcentaje de recuerdo de noticias registrado durante el último tercio del informativo editado descendió progresivamente de un $38 \%$ a un $25 \%$, y ello con independencia del interés noticioso de las informaciones.

A continuación se incluye un gráfico que representa la evolución del recuerdo de noticias del informativo de televisión editado para la investigación:

\section{Gráfico $n^{o}$ 1: Recuerdo de información a lo largo de un informativo de televisión}

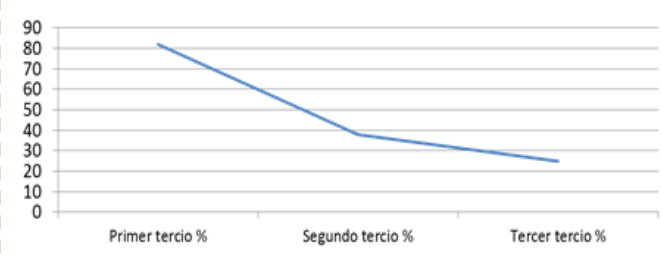

Fuente: Elaboración propia

La investigación tomó en cuenta la posible influencia que distintas variables socio-económicas y culturales pudieran ejercer en la forma de proce- 
sar el mensaje audiovisual. Se pudo comprobar que las variables analizadas "sexo", "edad", "clase social" y "formación académica" no influyeron en la obtención de resultados significativamente diferentes en el experimento en relación al número de noticias recordadas por los espectadores sin ayuda. Las investigaciones previas se centraron en el estudio de las variables "edad" y "formación académica" (Stauffer, Frost y Rybolt, 1983: 31-35; Morrow y Ryan, 2002: 373-380; Karrasch y Laine, 2003: 97-101).

Descubrieron que los grupos de voluntarios con menor edad recordaban un mayor volumen de información (Stauffer, Frost y Rybolt, 1983: 31-35), al igual que aquellos que poseían un mayor nivel educativo (Kleinnijenhuis, 1991: 499-522). Por el contrario, las últimas investigaciones publicadas no han encontrado una relación evidente entre el mayor o menor número de noticias recordadas por los espectadores y sus distintos tipos de formación (Grabe, Kamhawi y Yegiyan, 2009: 106-107). Los resultados del presente experimento apoyan esta última teoría. No se encontraron diferencias significativas entre grupos de mayor y menor edad.

La formación académica de los participantes tampoco resultó ser un factor determinante de un mayor o menor recuerdo de información. Las dos categorías delimitadas correspondieron a estudios primarios, secundarios y medios por un lado, y estudios superiores universitarios acabados, por el otro. Los dos grupos formados en función del nivel de estudios terminados comprendieron dos niveles formativos claramente definidos. Sin embargo, al contrario de lo que afirmaba la doctrina en los inicios (Stauffer, Frost y Rybolt, 1983: 31-35) y a principio de la década de los años 2000 (Morrow y Ryan, 2002: 373-380; Karrasch y Laine, 2003: 97-101), no se detectaron diferencias notables en el recuerdo de noticias del informativo. Los resultados del experimento sí se suman a lo descubierto por Grabe et al. en fechas más recientes (Grabe, Kamhawi y Yegiyan 2009: 106-107).

En ese sentido, puede decirse que la competencia mediática para interpretar el mensaje audiovisual parece haber alcanzado una cierta homogeneidad en la audiencia de informativos de televisión en España a finales de la primera década del siglo XXI, con independencia del factor "formación académica". El nivel de estudios alcanzado, que en el pasado resultó ser una variable mucho más influyente en la decodificación de un mensaje elaborado en función de una pluralidad de códigos (texto, imágenes y sonidos), no parece ser en la actualidad tan relevante como 
posiblemente lo sean otros factores específicamente relacionados con el modo de interpretar la información audiovisual en este nuevo siglo.

Resulta difícil determinar las causas por las cuales la muestra de participantes facilitó una respuesta unitaria en lo que se refiere al recuerdo de noticias del informativo. Una posible explicación ya se ha anunciado previamente: Drew y Grimes (1987: 452-453) recogen las teorías formuladas por los psicólogos especializados en asuntos cognitivos que afirman que el sistema humano de procesamiento de información es limitado. Pero existen otras posibles causas. Estudios llevados a cabo en los Países Bajos indican que los espectadores con un nivel educativo más bajo recuerdan mejor la información audiovisual que la escrita. Se afirma que el mensaje en televisión se presenta y redacta en un lenguaje que pertenece al registro conversacional. De esta forma el mensaje puede ser comprendido en una única exposición y verse apoyado por una explicación de tipo visual (Kleinnijenhuis, 1991: 499-522).

Podría ocurrir que los espectadores con un menor nivel educativo alcanzasen el mismo nivel que los que poseen una mayor formación en lo que respecta al recuerdo de información audiovisual emitida en televisión. Ello justifi- caría en parte los resultados obtenidos en la encuesta realizada en la investigación. De cualquier modo, se deja la puerta abierta a futuras investigaciones sobre este aspecto de la investigación que permitan obtener un conocimiento más profundo del comportamiento de la audiencia en relación a esta variable.

Los estudios sobre el número de noticias recordadas por la audiencia no contemplaron en el pasado el estudio de las variables "sexo" y "clase social". En esta investigación se analizan por primera vez las diferencias de género en los estudios sobre coordinación entre códigos audiovisuales. En relación al sexo de los participantes, se pudo comprobar que no existen diferencias sustanciales en las respuestas dadas por hombres y mujeres. Si bien es cierto que las mujeres son capaces de recordar sin ayuda casi una noticia más que los hombres, este hecho no revela realmente una mayor capacidad del sexo femenino para recordar más noticias.

El factor "clase social" se analizó en esta investigación tomando únicamente en consideración el comportamiento de la clase media en tres niveles: bajo, medio y alto. Las clases sociales baja y alta no se incluyeron en el experimento debido a que el diseño de la muestra se centró en la información comercial proporcionada por las cadenas de tele- 
visión contactadas. El único estudio posible del factor "clase social" en esta investigación se circunscribe a la clase social media, lo que debe ser tenido en cuenta a la hora de analizar los resultados en relación a esta variable.

En todo caso, se estima que en el recuerdo del mensaje informativo en televisión influyen otros factores además de la clase social, ya que el interés de la audiencia se define no solo por su estatus social, sino también por otros factores como la edad, los gustos personales, la proximidad del tema con los propios espectadores, etc. En ese sentido se ha pronunciado un sector doctrinal: la investigadora Mallory Wober no encontró diferencias significativas entre espectadores británicos de distinta clase social en relación al interés que expresaron por la temática de una serie de noticias emitidas por

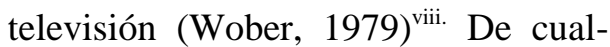
quier modo, y únicamente en lo que respecta a la clase social media, puede afirmarse que no se detectaron en la investigación emprendida, diferencias sustanciales entre los integrantes de la clase social media en sus estratos bajo, medio y alto. Posiblemente una investigación posterior con un diseño de la muestra más amplio que incluyese a todas las clases sociales y no se ciñera al perfil comercial de las cadenas de televisión de nuestro país podría aportar datos complementarios que se sumasen a los registrados en esta ocasión.

\section{Las relaciones entre los códigos audiovisuales en los informativos de televisión}

El procesamiento de información audiovisual en función de las relaciones entre los códigos, es decir, la forma más o menos estrecha- en que el texto, las imágenes y los sonidos se relacionan para elaborar una noticia en el medio televisivo se analizó en piezas informativas construidas en función de distintas estructuras narrativas, forma- tos y tipos de imágenes, entre otras variables.

Como regla general, las informaciones mejor recordadas y comprendidas por la audiencia son aquellas que consiguen coordinar de forma estrecha el texto, las imágenes y los sonidos. Los espectadores recuerdan y comprenden con preferencia noticias con relaciones de complementariedad perfecta, aso- 
ciada al grado más alto de coordinación entre códigos posible. No obstante, se constata que la relación de complementariedad perfecta reduce ostensiblemente su eficacia en el recuerdo y comprensión de información cuando en las piezas se introducen acumulativamente variables susceptibles de alterar el procesamiento normalizado del mensaje como la saturación informativa y la presencia de "imágenes llamativas" de signo negativo, es decir aquellas que representan hechos de carácter dramático o con efectos negativos (por ejemplo, catástrofes naturales, enfrentamientos y conflictos, etc.) sin llegar a absorber la atención del espectador como lo hacen las imágenes de impacto emotivo, también conocidas como "negative news visuals" o "bad news visuals" según la terminología empleada por la doctrina de habla inglesa (Newhagen, 1992: 25; Zhou, 2004: 237). Sin duda, estos recursos constituyen estímulos asociados a la cultura del "infoespectáculo". A pesar de que es habitual encontrar a diario en los informativos de televisión una sobreabundancia de llamadas de atención al espectador, los resultados de la investigación parecen contradecir los beneficios, en todos los casos, de esta práctica común entre los profesionales de la televisión de nuestros días.

Se ha dicho que las noticias resultan más fáciles de comprender y recordar cuanto mayor es el grado de conexión entre códigos audiovisuales. No obstante, se comprueba que existen casos en que el nivel de coordinación entre el audio y el video no influye de forma determinante en el procesamiento del mensaje audiovisual y que son otros factores como, por ejemplo, el uso de determinados formatos como el directo o el VTR los que más favorecen la recuperación de información. En efecto, la investigación registró una mayor eficacia de los formatos VTR y directo a la hora de almacenar y recuperar información de la memoria de los espectadores en relación a otros estudiados como las colas y los totales. Casi el $90 \%$ de los participantes en el experimento de la investigación recordó piezas elaboradas con un formato VTR o bien emitidas en directo. El porcentaje de espectadores que recordaron piezas concretas descendió al 46,6\% en el caso de los totales y al $38,3 \%$ en el de las noticias editadas como colas.

A continuación se presenta un gráfico que recoge los porcentajes de recuerdo de noticias en función de la variable "formatos": 


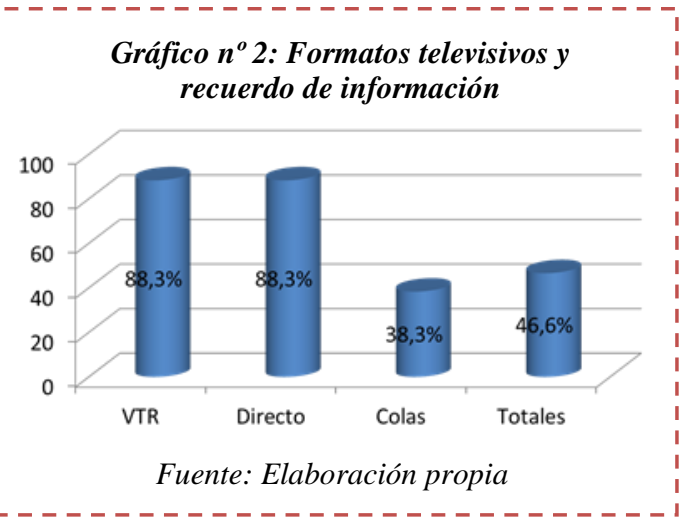

Por otra parte, informaciones elaboradas con grados más bajos de coordinación obtienen una respuesta positiva de los espectadores en lo que respecta al recuerdo efectivo de datos del mensaje así como a su comprensión. Informaciones con grados de coordinación bajos como aquellas que incluyen una relación de jerarquía parcial son recordadas y comprendidas con eficacia cuando en la transmisión del mensaje se incluyen variables como técnicas de recapitulación de información. Estas demostraron ser un recurso relativamente eficaz para mejorar el recuerdo de información ya que se registró un aumento del recuerdo de información por los espectadores que osciló entre el $8,4 \%$ y el $18,3 \%$ en relación a informaciones que no incluyeron ni rótulos de texto ni titulares respectivamente.

También se ha comprobado la eficacia de noticias con grados medios de coordinación entre códigos que son recordadas y comprendidas en grado alto y medio-alto por los espectadores. Se trata de mensajes elaborados sobre la base de una relación de complementariedad imperfecta que utilizan determinadas estructuras narrativas audiovisuales para distribuir los hechos periodísticos como la cronológica o la denominada "pirámide diseminada" (Mayoral et al, 2008: 120) ${ }^{\mathrm{ix} .}$ Los niveles de recuerdo y comprensión registrados en este tipo de piezas informativas alcanzan cifras cercanas a las de noticias elaboradas con una relación de complementariedad perfecta apoyada por recursos que favorecen el procesamiento de datos como las "imágenes llamativas" que ilustran hechos positivos, denominadas en la investigación como de "signo positivo" (contrapuestas a las de "signo negativo").

Por último, y en relación a la variable "estructuras narrativas", los resultados de la encuesta a sesenta participantes revelaron que la forma de estructurar el relato en televisión también resulta relevante a la hora asimilar el mensaje audiovisual. Los resultados demostraron que una narración cronológica de los hechos resulta más eficaz para mejorar el recuerdo y la comprensión de datos principales que la tradicional "pirámide invertida", tanto en informaciones que coordinan las imágenes y los sonidos de forma estrecha como en las que no. 
Los resultados registrados conducen a la conclusión de que existen opciones de recuerdo de información válidas que no se basan en una absoluta correspondencia entre códigos audiovisuales. Los resultados confirman las teorías enunciadas por Drew y Grimes
(1987: 459) sobre el recuerdo eficaz de noticias con menores grados de coordinación y al mismo tiempo aportan nuevos datos sobre las relaciones entre códigos más útiles para mejorar el procesamiento de información en televisión.

\section{Recuerdo y comprensión de información en presencia del código icónico}

La importancia que ha adoptado el código icónico en la sociedad mediática actual y, en particular, en los informativos de televisión, justificó un análisis algo más pormenorizado de este código audiovisual en la investigación. Se observó el comportamiento de la audiencia en relación a distintos tipos de imágenes como las meramente ilustrativas, las "llamativas" de distinto signo -positivo y negativo- y las impactantes. La imposibilidad material de efectuar una tipología exhaustiva de todas las clases de imágenes que se emiten en un informativo diario de televisión obligó a limitar el análisis a aquellas que se utilizan con mayor frecuencia en las redacciones de los programas informativos para editar las distintas piezas de los noticiarios.

El procesamiento del código icónico fue analizado en relación a las informaciones que contienen imágenes con un alto impacto emotivo. La investiga- ción aportó datos respecto a la comprensión de información en noticias con imágenes impactantes, un aspecto aun no abordado por trabajos anteriores que se limitaron a observar solamente los efectos en la retención. En noticias con un grado estrecho de concordancia entre el audio y el video, los espectadores comprenden efectivamente datos narrados verbalmente antes y después de la emisión de las imágenes de impacto, pero no así durante su emisión.

En relación al recuerdo, los mejores datos se registraron tras la emisión de las imágenes de impacto, por lo que los resultados podrían superar la conocida teoría de la "doble codificación" de Robinson y Levy (1986: 129-135) ya que una alta concordancia entre códigos sólo favorece el recuerdo de información verbal emitida tras la emisión de los estímulos altamente emotivos, pero no así antes o durante 
su aparición en pantalla como afirmaban los autores. Se comprobó que la audiencia pierde información verbal anterior y simultánea a unas imágenes de impacto fuertemente coordinadas con la narración en un porcentaje estimado del $17 \%$.

Por otro lado, se advierte que se han detectado indicios de que el código icónico podría recordarse igual o mejor que el lingüístico antes de la aparición de unas imágenes de impacto con independencia del grado de coordinación entre códigos audiovisuales.

Además, se observó que la presencia de imágenes impactantes, tanto en noticias como en titulares de un informativo, consigue modificar el procesamiento sistemático de información en piezas elaboradas con distintos grados de coordinación. Informaciones editadas con un bajo grado de concordancia entre el audio y el video durante la emisión de imágenes altamente emotivas alcanzan índices de recuerdo y de comprensión más elevados que aquellas construidas con grados de correspondencia entre códigos más estrechos. Se estima como posible causa de este comportamiento el incremento del nivel de atención alcanzado por la audiencia al tener que realizar un sobreesfuerzo para descodificar un mensaje diseñado con un bajo nivel de coordinación entre códigos audiovisuales y un mayor grado de complejidad originado por la presencia de imágenes impactantes.

Se recuerda que la audiencia replica este comportamiento en noticias con saturación informativa provocada por una presencia acumulativa y excesiva de estímulos visuales, sonoros y auditivos. Un alto grado de coordinación no asegura tasas de recuerdo más altas ni tampoco una mejor comprensión del mensaje cuando interviene el factor "saturación informativa". Por el contrario, el recuerdo y la comprensión son superiores cuanto menor es la correspondencia entre códigos audiovisuales. En relación a esta variable se señala que, a diferencia de otros casos analizados, el recuerdo y la comprensión no interactúan en el procesamiento de información por los espectadores. Con independencia del grado de coordinación entre códigos, la audiencia no fue capaz de recordar alrededor del $50 \%$ del contenido de un mensaje con saturación de estímulos audiovisuales. Sin embargo, el grado de error en el recuerdo de información -vinculado con el nivel de comprensión de los espectadores- no fue tan elevado ni en informaciones con un alto grado de coordinación entre códigos (12\%) ni en otras editadas con una menor concordancia $(7,3 \%)$. 


\section{Conclusiones}

La investigación llevada a cabo presenta un conjunto de "buenas prácticas" sobre como se puede mejorar la eficacia comunicativa de los mensajes informativos en el medio televisivo siguiendo unas pautas de coordinación concreta entre códigos audiovisuales. Suministra información útil a los profesionales de la información en televisión y al mismo tiempo permite obtener datos relevantes sobre el comportamiento de la audiencia, sus capacidades y limitaciones cognitivas que permitirán elaborar con mayor eficacia los mensajes emitidos en el medio televisivo en el futuro.

El análisis histórico de las relaciones entre códigos audiovisuales reveló una evolución en el modo de elaborar el mensaje audiovisual. Durante la década de 1970 el medio televisivo tendía a imitar la narración propia de la prensa escrita pero a finales de la década de 2000 el relato audiovisual se inspira en normas propias que han ido renovándose con el paso del tiempo.

El predominio inicial de la narración verbal y de la relación de jerarquía total del código lingüístico ha dado lugar a una introducción progresiva de otro tipo de relaciones entre códigos que han originado diferentes grados de correspondencia entre la narración, los textos sobreimpresionados en pantalla, las imágenes y el sonido. Los años 2000 se han caracterizado por una mayor presencia de relaciones de complementariedad entre códigos que se coordinan de forma más estrecha para dar lugar a una exposición del mensaje informativo más compleja y completa. Cada código asume un papel concreto en la transmisión de datos esenciales o accesorios del mensaje y sirve para comunicar emociones en distintos grados susceptibles de influir en el recuerdo y en la comprensión de información por los espectadores.

En relación al código icónico, se detecta en la actualidad una mayor presencia y uso de diversos tipos de imágenes de naturaleza emotiva como las imágenes de impacto y las llamativas de distinto signo, que provocan efectos en el procesamiento de información en función del grado de conexión entre los códigos audiovisuales. Además, las imágenes se toman mucho más en cuenta a la hora de elaborar el mensaje en relación a épocas pasadas.

El procesamiento del mensaje difiere en función de las relaciones entre códigos audiovisuales y su correspondiente grado de coordinación entre 
elementos audiovisuales. Los resultados de la investigación demostraron que la coordinación entre los códigos lingüístico, icónico y sonoro aumenta la comprensión y retención del mensaje por la audiencia en un número estimable de opciones informativas que combinan los códigos audiovisuales en función de variables como las estructuras narrativas, las técnicas de recapitulación de información o la presencia de determinado tipo de imágenes.

La relación de complementariedad perfecta demostró ser la más eficaz para lograr un mejor recuerdo y comprensión de datos, aunque pierde efectividad cuando en el mensaje se introducen variables como la saturación informativa o imágenes llamativas de signo negativo. Se observó que las imágenes llamativas positivas, sin embargo, tienden a facilitar el procesamiento de información.

Otras variables que también contribuyen a mejorar el recuerdo y la comprensión de información en piezas con grados medios de coordinación entre códigos son formatos como el VTR y el directo o las estructuras narrativas en forma de "pirámide diseminada" y cronológica. Los efectos se comprobaron especialmente en relaciones de complementariedad imperfecta.

Los resultados de la investigación también evidenciaron que existen fór- mulas alternativas de comprensión y recuerdo del mensaje por los espectadores que se caracterizan por una interacción de factores más compleja y una correspondencia entre códigos menos estrecha. Así, piezas elaboradas sobre la base de una relación de jerarquía parcial pueden ser descodificadas con eficacia cuando se emplean técnicas de recapitulación de información que ayudan a recordar el contenido del mensaje. Su eficacia se demostró en relación al uso de titulares que consiguen incrementar un $18 \%$ el recuerdo de información. En el mismo sentido, los rótulos de texto permiten aumentar la eficacia del recuerdo en un $8 \%$.

Informaciones con grados bajos de coordinación entre códigos audiovisuales son recordadas y comprendidas con eficacia por la audiencia cuando se introducen imágenes impactantes. La audiencia recuerda con mayor facilidad la información verbal emitida con anterioridad y posterioridad a unas imágenes de impacto, pero no así durante su emisión. Se presupone un aumento del nivel de atención de la audiencia como posible explicación de este fenómeno que se reproduce en noticias con saturación informativa. En este tipo de piezas los telespectadores solo consiguen recordar el $50 \%$ del total del mensaje. No obstante, la comprensión no resulta tan afectada por el exceso de estímulos audiovisua- 
les ya que una amplia mayoría asimila fácilmente el contenido del mensaje tanto en piezas con un menor grado de coordinación entre códigos (93\% del mensaje) como con un mayor nivel de correspondencia (88\%).

Los datos registrados en la investigación sobre la habilidad de los televidentes para almacenar y recuperar información audiovisual confirman la vigencia de las teorías sobre la capacidad limitada de la audiencia. Los espectadores solo pueden recordar sin ayuda el 35\% del total de noticias de un informativo de televisión de corta duración. El $80 \%$ de la audiencia recuerda fácilmente el contenido del primer tercio de un programa informativo pero su atención desciende después de forma progresiva. La audiencia sufre una importante pérdida de concentración transcurridos diez minutos tras el inicio del noticiario, lo que revela una dificultad manifiesta para concentrar la atención más allá de ese límite. En el último tercio se contabiliza una pérdida del $75 \%$ del nivel global de atención con independencia de la edad, el sexo, la formación o la clase social de los espectadores. En ese aspecto puede afirmarse que, en la actualidad, existe homogeneidad en la competencia mediática de la audiencia de televisión.

La investigación ha analizado formas tradicionales de elaboración del mensaje en el medio televisivo pero también modos de expresión vinculados con la cultura del "infoespectáculo" que aparecen cada vez con mayor asiduidad en los informativos de televisión de comienzos del siglo XXI. Estas nuevas formas de relacionar la narración, las imágenes y los sonidos están dando lugar al nacimiento de nuevas reglas de la gramática audiovisual que deberán ser tenidas en cuenta de ahora en adelante en el medio televisivo.

\section{Referencias}

ASOCIACIÓN PARA LA INVESTIGACIÓN DE MEDIOS DE COMUNICACIÓN (2011). Estudio General de Medios (EGM). [Tercera oleada 2011]. [s.1.],Recuperado (3 de febrero de 2012) de http://www.aimc.es/Entrega-deresultados-EGM-3\%C2\%AA-ola.html

BARROSO GARCÍA, Jaime (1992). Proceso de la información de actualidad en televisión. Madrid, Instituto Oficial de Radio y Televisión. Radiotelevisión Española.
BERRY, Colin (1983). "Learning from Television News: A Critique of the Research", en Journal of Broadcasting, Vol. 27, $\mathrm{n}^{\circ}$ 4. [s.1.], Broadcast Education Association, pp. 359-70.

BOURDIEU, Pierre (1996). Sur la télévision. Paris, Liber. Raisons d'agir.

BROSIUS, Hans-Bernd; DONSBACH, Wolfgang y BIRK, Monika (1996). "How do textpicture relations affect the informational effectiveness of television newscasts?", en Journal of Broadcasting \& Electronic Media, Vol. 40, 
$\mathrm{n}^{\circ}$ 2. [s.1.], Broadcast Education Association, pp. 180-195.

CASTELLS, Manuel (2004). "Informationalism, networks, and the network society: a theoretical blueprint", en CASTELLS, Manuel. The Network Society: a cross-cultural perspective, Northampton, Edward Elgar, p.3.

DREW, Dan G. y GRIMES, Thomas (1987). "Audio-visual Redundancy and Tv news recall", en Communication Research, Vol. 14, $\mathrm{n}^{\circ}$ 4. [s.1.], SAGE Publications, pp. 452-461.

GRABE, Maria Elizabeth; KAMHAWI, Rasha y YEGIYAN, Narine (2009). "Informing citizens: how people with different levels of education process television, newspaper and web news", en Journal of Broadcasting \& Electronic Media, Vol. 53, $\mathrm{n}^{\circ}$ 1. [s.1.], Broadcast Education Association, pp. 90-111.

KARRASCH, M. y LAINE, M. (2003). “Age, education and test performance on the Finnish CERAD", en Acta Neurologica Scandinavica, Vol. 108, n ${ }^{\circ}$ 2. [s.1.], John Wiley and Sons A/S, pp.97-101.

KATZ, Elihu; ADONI, Hanna y PARNESS, Pnina (1977). "Remembering the news: what the picture add to recall", en Journalism Quarterly, Vol. 54, $\mathrm{n}^{\circ}$ 2. Columbia, Association for Education in journalism and Mass Communication, pp. 231-239.

KLEINNIJENHUIS, J. (1991). "Newspaper complexity and the knowledge gap", en European Journal of Communication, Vol. 6, $\mathrm{n}^{\circ} 4$. [s.1.], SAGE Publications, pp. 499-522.

LANG, Annie; NEWHAGEN, John y REEVES, Byron (1996. "Negative video as structure: emotion, attention, capacity and memory", en Journal of Broadcasting \& Electronic Media, Vol. 40, no 4. [s.1.], Broadcast Education Association, pp. 460-477.

MAYORAL, Javier (coord.); SAPAG, Pablo; HUERTA, Armando y DÍEZ, Francisco Javier (2008). Redacción periodística en televisión. Madrid, Editorial Síntesis.

MORROW, L.A. y RYAN, C. (2002)."Normative data for a short-term work- ing memory test: The four word short-term memory test", en The Clinical Neuropsychologist, Vol. 6, $\mathrm{n}^{\circ}$ 3. [s.1.], Psychology Press, pp. 373-380.

NEWHAGEN, John E. (1992). "The evening's bad news: effects of compelling negative television news images on memory", en Journal of Communication, Vol. 42, $\mathrm{n}^{\circ}$ 2. Austin (Texas), International Communication Association, pp. 25-41.

ORIVE RIVA, Pedro (1988). Los españoles ante los Telediarios. Madrid, Asociación de Estudios de Comunicación para las Autonomías (AECAS).

\section{PRÓSPER, José y LÓPEZ CATALÁN}

Celestino J. (1998). Elaboración de noticias y reportajes audiovisuales. Valencia, Fundación Universitaria San Pablo CEU.

ROBINSON, John P. y LEVY, Mark R. (1996). "News media use and the informed public: a 1990s update", en Journal of Communication, Vol. 46, $\mathrm{n}^{\circ} 2$. Austin (Texas), International Communication Association, pp. 129-135.

SON, J.; REESE, S. D. y DAVIE, W. R. (1987). "Effects of visual-verbal redundancy and recaps on television news learning", en Journal of Broadcasting \& Electronic Media, Vol. 31, $\mathrm{n}^{\circ}$ 2. [s.1.], Broadcast Education Association, pp. 207-216.

STAUFFER, John; FROST, Richard y RYBOLT, William (1983). "The attention factor in recalling network television news", en Journal of Communication, Vol. 33, $\mathrm{n}^{\circ} 1$. Austin (Texas), International Communication Association, pp. 29-37.

ZHOU, Shuhua (2004). "Effects of visual intensity and audiovisual redundancy in bad news", en Media Psychology, Vol. 6, nº 3. [s.l.], Routledge, pp. 237-256.

ZHOU, Shuhua (2005). "Effects of arousing visuals and redundancy on cognitive assessment of television news", en Journal of Broadcasting \& Electronic Media, Vol. 49, nº 1. [s.l.], Broadcast Education Association, pp. 2342. 


\section{Cita de este artículo}

Benaissa Pedriza, S. (2012) La comprensión y retención del mensaje informativo por la audiencia de televisión. Icono14 10(3), 202-227, doi: 10.7195/ri14.v10i3.171

\section{NOTAS}

${ }^{i}$ El sociólogo Manuel Castells se inspira en el término empleado con anterioridad por Jan van Dijk en su obra De Netwerkmaatschappij (La Sociedad Red), publicada a principios de la década de 1990 cuando la generalización de las nuevas tecnologías de la información y de la comunicación permitió el desarrollo de la sociedad en red tal y como la conocemos en la actualidad.

ii La relación de jerarquía total entre códigos es aquella en que el código icónico o lingüístico ostenta una relevancia predominante en relación al otro código en términos de atención del espectador e importancia informativa. Son los casos de la noticia leída y de las imágenes que no van acompañadas de texto alguno.

iii En la relación de jerarquía parcial se produce el protagonismo del código icónico o del lingüístico sobre otros códigos, sin llegar a anular la presencia del código opuesto. Puede darse un protagonismo del texto y ser las imágenes de tipo ilustrativo, o bien un protagonismo de la imagen y ser el texto de tipo aclaratorio. Asimismo, puede darse un protagonismo del código sonoro y ser la imagen o el texto de tipo ilustrativo o aclaratorio.

${ }^{\text {iv }}$ La relación de complementariedad perfecta indica una relación de equilibrio total entre el código icónico, lingüístico y/o sonoro. Sería el caso de las informaciones en las que uno de los códigos aporta información en el mismo grado de relevancia que el otro, sin poder prescindir de ninguno de los códigos para la eficaz comprensión del mensaje informativo por la audiencia.

${ }^{v}$ En la relación de complementariedad imperfecta se da una relación de subordinación de uno de los códigos, icónico o lingüístico, en relación al otro, en la expresión de elementos relevantes del mensaje informativo. Las relaciones de complementariedad imperfecta aparecen en las informaciones en las que, sin llegar a producirse un predominio absoluto de uno de los códigos, los elementos esenciales del mensaje informativo se transmiten recurriendo con mayor frecuencia a uno de los códigos.

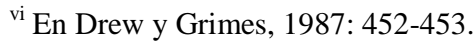

vii Ibídem.

viii En Berry, 1983: 365.

ix La llamada "pirámide diseminada" distribuye la información relevante a lo largo de toda la pieza, y no en los primeros momentos de emisión, con el fin de sostener la atención del telespectador hasta el final. 